\title{
Besnoitia besnoiti-driven endothelial host cell cycle alteration
}

\author{
Zahady D. Velásquez ${ }^{1}$ (1) - Sara Lopez-Osorio ${ }^{1,2}$ - Learta Pervizaj-Oruqaj ${ }^{3,4,5}$. \\ Susanne Herold ${ }^{3,4,5} \cdot$ Carlos Hermosilla $^{1} \cdot$ Anja Taubert $^{1}$
}

Received: 15 January 2020 / Accepted: 1 June 2020 / Published online: 17 June 2020

(C) The Author(s) 2020

\begin{abstract}
Besnoitia besnoiti is an important obligate intracellular parasite of cattle which primarily infects host endothelial cells of blood vessels during the acute phase of infection. Similar to the closely related parasite Toxoplasma gondii, B. besnoiti has fast proliferating properties leading to rapid host cell lysis within 24-30 h p.i. in vitro. Some apicomplexan parasites were demonstrated to modulate the host cellular cell cycle to successfully perform their intracellular development. As such, we recently demonstrated that $T$. gondii tachyzoites induce G2/M arrest accompanied by chromosome missegregation, cell spindle alteration, formation of supernumerary centrosomes, and cytokinesis impairment when infecting primary bovine umbilical vein endothelial cells (BUVEC). Here, we follow a comparative approach by using the same host endothelial cell system for $B$. besnoiti infections. The current data showed that —in terms of host cell cycle modulation — infections of BUVEC by B. besnoiti tachyzoites indeed differ significantly from those by $T$. gondii. As such, cyclin expression patterns demonstrated a significant upregulation of cyclin E1 in B. besnoiti-infected BUVEC, thereby indicating parasite-driven host cell stasis at G1-to-S phase transition. In line, the mitotic phase of host cell cycle was not influenced since alterations of chromosome segregation, mitotic spindle formation, and cytokinesis were not observed. In contrast to respective $T$. gondii-related data, we furthermore found a significant upregulation of histone $\mathrm{H} 3$ (S10) phosphorylation in B. besnoiti-infected BUVEC, thereby indicating enhanced chromosome condensation to occur in these cells. In line to altered G1/S-transition, we here additionally showed that subcellular abundance of proliferating cell nuclear antigen (PCNA), a marker for G1 and S phase sub-stages, was affected by B. besnoiti since infected cells showed increased nuclear PCNA levels when compared with that of control cells.
\end{abstract}

Keywords Besnoitia besnoiti $\cdot$ Apicomplexan parasites $\cdot$ Coccidia $\cdot$ Cell cycle arrest $\cdot$ Histone H3 S10

\section{Introduction}

The apicomplexan obligate intracellular protozoa Besnoitia besnoiti represents a coccidian parasite of major importance

Section Editor: Panagiotis Karanis

Zahady D. Velásquez

zahady.velasquez@vetmed.uni-giessen.de

1 Institute of Parasitology, Biomedical Research Center Seltersberg, Justus Liebig University, Schubertstr. 81, 35392 Giessen, Germany

2 Research Group CIVAB, School of Veterinary Medicine, Faculty of Agrarian Sciences, University of Antioquia, Medellín, Colombia

3 Cardio Pulmonary Institute (CPI), Giessen, Germany

4 Universities Giessen \& Marburg Lung Center (UGMLC), Giessen, Germany

5 German Center for Lung Research (DZL), Giessen, Germany in cattle industry. B. besnoiti infection was classified as an "emerging disease" in Europe by the European Food Safety Authority in 2010 (EFSA). Bovine besnoitiosis leads to severe skin alterations, vulvitis, vaginitis, orchitis, and infertility of bulls and cows among other signs (Gollnick et al. 2018). Consequently, this parasite causes significant losses in commercial cattle industry and impairs individual animal welfare (Dubey and Lindsay 1996; Dubey 2003; Cortes et al. 2014).

It is well-known that apicomplexan parasites significantly modulate their host cells to guarantee successful intracellular development and proliferation. As such, they influence numerous host cellular pathways, such as apoptosis, autophagy, cytoskeleton, metabolism, or immune reactions. In this context, some reports have indicated that tachyzoites of $T$. gondii dysregulate the host cellular cell cycle (Brunet et al. 2008; Molestina et al. 2008; Velásquez et al. 2019). The cell cycle of mammalian cells represents a highly regulated and complex processes that includes successive progression of distinct cell 
cycle phases (G0-G1; S, and G2-M), which finally leads to cell division via cytokinesis. The cell cycle begins with the G1-phase (Gap-phase 1). In this step, the cell synthetizes mRNA and proteins that the next cell cycle steps. Afterward, the cell triggers the DNA synthesis machinery to duplicate its complete genome, in the so-called S-phase. Once this process is completed, the cell enters into a new process of growing and synthetizing proteins, called the G2-phase. Finally, the cell activates the genome division process, called mitosis, which will give rise to two daughter cells with the same genome composition and size (M-phase and cytokinesis). The transition to each phase is tightly regulated by specific checkpoint proteins and is based on sequential activation or inactivation of cyclins, cyclin-dependent kinases (Cdk), and cyclindependent kinase inhibitors (CDK-inhibitor). For instance, G1-phase is regulated by D- and E-type cyclins, while Sphase is controlled by A-type cyclins and G2/M-phase Atype and B-type cyclins (Vermeulen et al. 2003). Cyclin and its CDK partner modulates an intracellular signal that allows for the cell cycle progression. On the contrary, CDKinhibitors regulate the cyclins-CDK complex activity and/or degradation to allow the correct cell cycle development.

In case of protozoan infections, data indicate a speciesspecific host cellular cell cycle dysregulation. As such, T. gondii and Leishmania spp. induce cell cycle arrest and eventually dampen host cell proliferation (Brunet et al. 2008; Costales et al. 2009; Kim et al. 2016; Kuzmenok et al. 2005; Molestina et al. 2008; Scanlon et al. 2000; Velásquez et al. 2019), while Theileria annulata and Theileria parva trigger host cell division and proliferation (von Schubert et al. 2010; Wiens et al. 2014) and induce segregation of Theileria merozoites to each developing daughter cell. Conversely, L. amazonensis interferes early in cell cycle by G0/G1-phase arrest (Kuzmenok et al. 2005). In contrast, Plasmodium falciparum infections of HepG2 cells affect mitosis and lead to a binucleated phenotype and a lack of cell division (Hanson et al. 2015). In the case of $T$. gondii, available data record different modes of action, on one side, an infection-driven shift from $\mathrm{G} 0 / \mathrm{G} 1$ to $\mathrm{S}$ phase with an accumulation of host cells in S phase (Molestina et al. 2008; Lavine and Arrizabalaga 2009). On the other side, a host cellular arrest in the G2 phase (Brunet et al. 2008) or even both (Kim et al. 2016), thereby most probably reflecting cell type-specific reactions. We recently reported that $T$. gondii infections of primary bovine umbilical vein endothelial cells (BUVEC) lead to a G2/M arrest and trigger severe defects during mitosis as propagated by chromosome missegregation, supernumerary centrosome formation, and cytokinesis impairment (Velásquez et al. 2019). Given that no data exist on $B$. besnoiti-triggered host cell cycle modulation, and also to generate comparative data with $T$. gondii, we here used the same type (BUVEC) for B. besnoiti infections in order to replicate in vivo infections as closely as possible and analyzed the impact of this obligate intracellular parasite on cell cycle progression. We here show for the first time that $B$. besnoiti infection indeed alters cell cycle-related molecules (e.g., cyclin E1, p27-kip1) but differs in its effects from $T$. gondii, therefore modulating host endothelial cell cycle progression in a parasite species-specific manner.

\section{Material and methods}

\section{Primary bovine umbilical vein endothelial cell isolation and maintenance}

Primary bovine umbilical vein endothelial cells (BUVEC) were isolated from umbilical veins obtained from calves born by sectio caesarea at the Justus Liebig University Giessen. Therefore, umbilical cords were kept at $4{ }^{\circ} \mathrm{C}$ in $0.9 \%$ HBSS-HEPES buffer (pH 7.4; Gibco, Grand Island, NY, USA) supplemented with $1 \%$ penicillin $(500 \mathrm{U} / \mathrm{ml}$; Sigma, St. Louis, MO, USA) and streptomycin $(500 \mu \mathrm{g} / \mathrm{ml}$; Sigma $)$ for a maximum of $16 \mathrm{~h}$ before use. For the isolation of endothelial cells, $0.025 \%$ collagenase type II (Worthington Biochemical Corporation) suspended in Pucks solution (Gibco) was infused into the lumen of ligated umbilical veins and incubated for $20 \mathrm{~min}$ at $37{ }^{\circ} \mathrm{C}$ in $5 \% \mathrm{CO}_{2}$ atmosphere. After gently massaging the umbilical veins, the cell suspension was collected in cell culture medium and supplemented with $1 \mathrm{ml}$ fetal calf serum (FCS, Gibco) in order to inactivate collagenase. After two washes $(350 \times g, 12 \mathrm{~min}, \mathrm{RT})$, cells were resuspended in complete endothelial cell growth medium (ECGM, PromoCell, supplemented with $10 \%$ FCS), plated in $25-\mathrm{cm}^{2}$ tissue plastic culture flasks (Greiner) and kept at $37{ }^{\circ} \mathrm{C}$ in $5 \% \mathrm{CO}_{2}$ atmosphere. BUVEC were cultured in modified ECGM medium (EGCM, diluted at 30\% in M199 medium, supplemented with 5\% FCS (Greiner) and 1\% penicillin and streptomycin) with medium changes every $2-3$ days. BUVEC cell layers were used for infection after 3 passages in vitro. All bovine primary endothelial cells samples were conducted in accordance with the Institutional Ethics Commission of Justus Liebig Universität of Gießen (Germany), and in accordance with the current European Animal Welfare Legislation: ART13TFEU.

\section{Parasite tachyzoite maintenance}

Tachyzoites of Besnoitia besnoiti (strain Bb1Evora03) were maintained by serial passages either in primary bovine umbilical vein endothelial cells (BUVEC) or African green monkey kidney epithelial cells (MARC-145) according to (Muñoz Caro et al. 2014). Confluent BUVEC monolayers in $25-\mathrm{cm}^{2}$ flasks were infected with $2.5 \times 10^{5}$ freshly isolated $B$. besnoiti tachyzoites. From 48 h p.i. onwards, free-released viable tachyzoites were collected from BUVEC culture supernatants, 
filtered through a 5- $\mu \mathrm{m}$ syringe filter (Sartorius AG), washed in modECGM and pelleted $(400 \times \mathrm{g}, 12 \mathrm{~min})$. Tachyzoites were counted in a Neubauer chamber and suspended in modECGM until further experimental use.

\section{Protein extraction}

Proteins from infected and non-infected BUVEC were extracted by cell sonication ( $20 \mathrm{~s}, 5$ times) in RIPA buffer (50 mM Tris-HCl, pH 7.4; $1 \% \mathrm{NP}-40 ; 0.5 \% \mathrm{Na}-$ deoxycholate; $0.1 \%$ SDS; $150 \mathrm{mM} \mathrm{NaCl} ; 2 \mathrm{mM}$ EDTA; $50 \mathrm{mM} \mathrm{NaF}$, all Roth) supplemented with a protease inhibitor cocktail (Sigma-Aldrich). Cell homogenates were centrifuged $\left(10,000 \times g, 10 \mathrm{~min}, 4^{\circ} \mathrm{C}\right)$ to sediment intact cells and nuclei. The protein content of RIPA buffer-soluble cell supernatant was quantified via Coomassie Plus (Bradford) Assay Kit (Thermo Scientific) following the manufacturer's instructions. Same protocol was applied for the tachyzoites protein extract production.

\section{Cell nuclei extraction}

Four BUVEC isolates were seed in T-25 flasks and infected with $B$. besnoiti (MOI 1:5). For controls, non-infected cells were used. After $24 \mathrm{~h}$ p.i., cells were detached by a cell scraper (Thermo Fisher Scientific) and collected in $500 \mu \mathrm{L}$ fractionation buffer (20 mM HEPES, pH 7.4, $10 \mathrm{mM} \mathrm{KCL,} 2 \mathrm{mM}$ $\mathrm{MgCl}_{2}, 1$ mM EDTA, 1 mM EGTA, 1 mM DTT, and protease inhibitor cocktail, Thermo Fisher Scientific). Cells were incubated for $15 \mathrm{~min}$ on ice, passed 10 times through a 27-gauge needle and kept on ice for $20 \mathrm{~min}$. To separate nuclear and cytoplasmic fractions, samples were centrifuged at $720 \times \mathrm{g}$ for $5 \mathrm{~min}$. The pellet (nuclear fraction) was washed thrice in $500 \mu \mathrm{l}$ fractionation buffer, and thereafter, nuclei were disrupted by passing through a 25 -gauge needle (10x). Nuclear proteins were then obtained by centrifugation at $700 \times g$ for $10 \mathrm{~min}$.

\section{SDS-PAGE and immunoblotting}

For immunoblotting, samples were supplemented with $6 \mathrm{M}$ urea. After boiling $\left(95^{\circ} \mathrm{C}, 5 \mathrm{~min}\right)$, total proteins $(60 \mu \mathrm{g} / \mathrm{slot})$ were separated in polyacrylamide gels (12\% or $15 \%)$ via electrophoresis (100 V, $1.5 \mathrm{~h}$; tetra system, BioRad). Proteins were transferred to polyvinylidene difluoride (PVDF) membranes (Millipore) (300 mA, $2 \mathrm{~h})$. Blots were blocked in 3\% BSA in TBS (50 mM Tris-Cl, pH 7.6; $150 \mathrm{mM} \mathrm{NaCl}$ containing $0.1 \%$ Tween (blocking solution); Sigma-Aldrich) for $1 \mathrm{~h}$ at RT and then incubated in primary antibodies (see Table 1) diluted in a blocking solution (overnight, $4{ }^{\circ} \mathrm{C}$ ). Detection of vinculin was used as loading control for normalization of samples. Following three washings in TBS-Tween $(0.1 \%)$ buffer, blots were incubated in adequate secondary antibody
Table 1 Primary antibodies used for western blot and immunofluorescence Primary antibodies

\begin{tabular}{lllll}
\hline Antigen & Company & Cat. number & Origin & Dilution \\
\hline Vinculin & Santa Cruz & sc-73614 & Mouse & $1: 1000$ \\
Cyclin A2 & Abcam & ab39 & Mouse & $1: 1000$ \\
Cyclin B1 & Abcam & ab32053 & Rabbit & $1: 3000$ \\
Cyclin B1 S126 & Abcam & ab133439 & Goat & $1: 1000$ \\
Cyclin E1 & Abcam & ab133266 & Rabbit & $1: 1000$ \\
Histone H3 S10 & Abcam & ab5176 & Rabbit & $1: 1000$ \\
PCNA & Abcam & ab18197 & Rabbit & $1: 1000$ \\
$\alpha$-Tubulin & Thermo Fisher & A11126 & Mouse & $1: 100$ \\
\hline
\end{tabular}

solutions (diluted in blocking solution, for dilution: see Table 1; $30 \mathrm{~min}, \mathrm{RT}$ ). Following three further washings in TBS-Tween buffer, signal detection was accomplished by an enhanced chemiluminescence detection system (ECL $®$ plus kit, GE Healthcare) and recorded using a ChemoCam Imager (Intas Science Imaging). Protein masses were controlled by a protein ladder (PageRuler Plus ${ }^{\circledR}$ Prestained Protein Ladder $10-250 \mathrm{kDa}$, Thermo Fisher Scientific). Protein band intensity quantification was analyzed using a Fiji Gel Analyzer ${ }^{\circledR}$ plugin. For all protein analyzed, the parasitic homologous protein was detected (data not shown).

\section{Immunofluorescence assays}

Cell layers were fixed with paraformaldehyde $(4 \%, 15 \mathrm{~min}$, RT), washed thrice with PBS and incubated in blocking/ permeabilization solution (PBS with 3\% BSA, $0.1 \%$ saponin; $1 \mathrm{~h}, \mathrm{RT}$ ). Thereafter, samples were incubated in primary antibodies (see Table 1) diluted in blocking/permeabilization solution (overnight, $4{ }^{\circ} \mathrm{C}$, in a humidified chamber). After three washings in PBS, samples were submitted to secondary antibody solution (see Table 2; 30 min, RT, darkness). Cell nuclei were labeled with 4',6-diamidin-2-phenylindol (DAPI) being present in mounting medium (Fluoromount $\mathrm{G}$, ThermoFisher, 495952).

\section{Flow cytometry-based analysis of cell cycle phases}

Cellular DNA content was measured using the FxCycle Far ${ }^{\circledR}$ red stain reagent (Invitrogen, F10348) according to the manufacturer's instructions. The samples were analyzed with a FACSCalibur ${ }^{\circledR}$ Analyzer (Becton-Dickinson, Heidelberg, Germany) applying 633/5 nm excitation and emission collected in a 660/20 bandpass. Cells were gated according to their size and granularity. Exclusively morphologically intact cells were included in the analysis. Data analysis was performed by 
Table 2 Secondary antibodies used for western blot and immunofluorescence

\begin{tabular}{lllll} 
Secondary antibodies & & & \\
\hline Name & Company & Cat. number & Reactivity & Dilution \\
\hline Goat anti-mouse IgG Peroxidase conjugated & Pierce & 31430 & Mouse & $1: 40000$ \\
Goat anti-rabbit IgG peroxidase conjugated & Pierce & 31460 & Rabbit & $1: 40000$ \\
AlexaFluor 488 & Thermo Fisher & A11008 & Rabbit & $1: 500$ \\
AlexaFluor 488 & Thermo Fisher & A11001 & Mouse & $1: 500$ \\
AlexaFluor 594 & Thermo Fisher & R37117 & Rabbit & $1: 500$ \\
AlexaFluor 594 & Thermo Fisher & A11005 & Mouse & $1: 500$ \\
\hline
\end{tabular}

the use of the FlowJo® (version 10.5.0) flow cytometry analysis software (FlowJo LLC, Ashland, OR).

\section{Confocal microscopy}

All immunofluorescence analyses were performed by confocal microscopy $(\times 63$ magnification with a numerical aperture of 1.4, LSM 710, Olympus). Two types of image acquisition were used: (i) multi-channel images which were merged to define the co-localization of the signal, and (ii) Z-stacks of $0.3-0.5 \mu \mathrm{m}$ for cell spindle and chromosome detection. Image processing was carried out by Fiji ImageJ® using Zprojection and merged-channel-plugins being restricted to overall adjustment of brightness and contrast.

\section{Live cell 3D-holotomographic microscopy}

3D-holotomographic images were obtained by using 3D Cell Explorer microscope (Nanolive ${ }^{\circledR} 3 \mathrm{D}$ ) equipped with an $\times 60$ magnification optic $(\lambda=520 \mathrm{~nm}$, sample exposure $0.2 \mathrm{~mW} /$ $\mathrm{mm} 2$ ) and a field depth of $30 \mu \mathrm{m}$. Images were analyzed using the STEVE® software (Nanolive) to obtain a refractive indexbased z-stack. Digital staining was applied according to the refractive index of intracellular structures. Nuclei were stained by DRAQ5 probe for vital DNA staining following the manufacturer instructions (DRAQ5 ${ }^{\text {TM }}$ Fluorescent Probe Solution, ThermoFischer).

\section{Statistical analysis}

The data from the total cell number in the monolayer and for WB assay were expressed as mean \pm SEM from six BUVEC isolates. For cell number- and FACS-based assays, one-way analysis of variance (non-parametric ANOVA) with KruskalWallis post-test was performed using the GraphPad Prism ${ }^{\circledR} 7$ software applying a significance level of $5 \%$. For immunoblot-based analyses, unpaired two-tailed $T$ tests were performed with Mann-Whitney post-test comparing controls vs infected cells, with a $95 \%$ confidence interval.

\section{Results}

\section{B. besnoiti infections do not affect host cell proliferation}

Even though B. besnoiti tachyzoites were recorded to successfully replicate in various immortalized host cell types (Cortes et al. 2007; Samish et al. 1988; Shkap et al. 1991), the kinetic of parasite division may differ depending on the host cell types infected in vivo. For this reason, we first estimated $B$. besnoiti division cycles in primary BUVEC by analyzing the number of tachyzoites present in each parasitophorous vacuole (PV) at a different time of infection (Fig. 1a). Using an MOI of 5:1 in three BUVEC isolates, we achieved an infection rate of 46.23 $\pm 14.73 \%$. Overall, we observed a non-synchronous proliferation of tachyzoites in BUVEC. First, tachyzoite division (detection of 2-mers) was observed at $6 \mathrm{~h}$ p.i.; from there onwards, an ongoing division was estimated and most tachyzoites had divided at $18 \mathrm{~h}$ p.i. (Fig. 1a). At $24 \mathrm{~h}$ p.i., 1to 32-mers were found in intracellular PVs (Fig. 1b).

The effect of $B$. besnoiti infections on host cell proliferation was examined by counting total BUVEC numbers. Given that we worked with a primary cell type, considerable variations in the size of cells and the time of cell division can be expected between isolates. Taking this into account, we included six biological replicates and used identical cell numbers for seeding. Given that $B$. besnoiti belongs to fast-replicating coccidian parasites and host cell lysis mainly occurs from $24 \mathrm{~h}$ p.i. onwards (thereby potentially inducing artifacts in host cell enumeration), we here restricted all host cell proliferation-based analyses to 1 day p.i. The determination of total host cell numbers revealed no statistically significant influence of $B$. besnoiti infections on host cell proliferation when compared with non-infected BUVEC controls (Fig. $1 \mathrm{~b}-\mathrm{c})$. Nevertheless, the analysis of each individual BUVEC isolate after $24 \mathrm{~h}$ p.i., which showed a decreasing tendency in the number of cells in the monolayer (Fig. 1c). This evidence was considered important because all samples, were seeded the same number and at the same time. Overall, four isolates from a total of six showed a decrease of the total amount of cells in the monolayer after $24 \mathrm{~h}$ p.i. Inter-donor variation in 
a

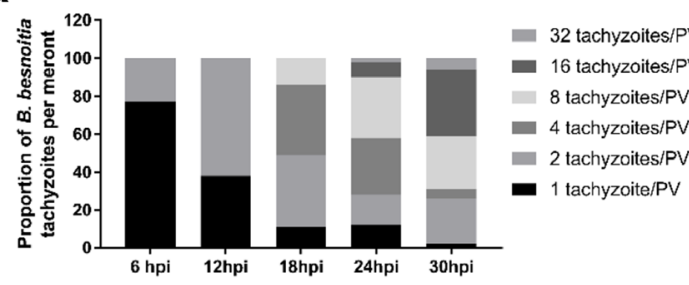

b
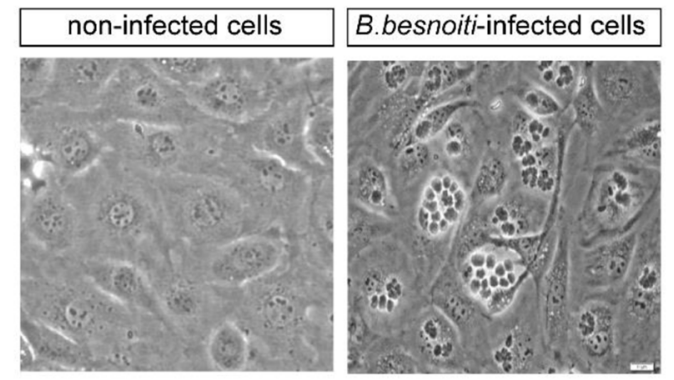

C

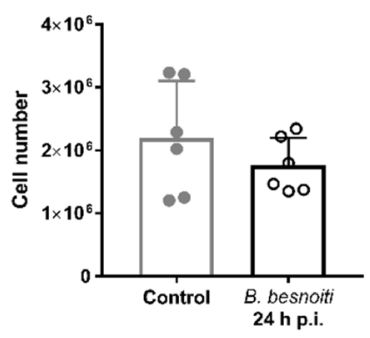

d

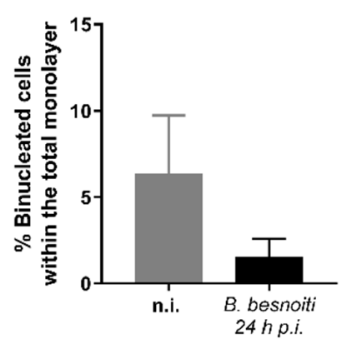

Fig. 1 Infection of BUVEC with B. besnoiti tachyzoites and effect of infection on host cell proliferation. Sub-confluent BUVEC were infected with $B$. besnoiti tachyzoites at an MOI 5:1 and analyzed after 24 hpi. a Quantification of tachyzoites numbers/parasitophorous vacuole during $30 \mathrm{~h}$ of infection. The mature structures were observed between 24 and $30 \mathrm{~h}$ p.i. After this time point, all parasites were released. b Illustration of non-infected control cells and B. besnoiti-infected BUVEC at $24 \mathrm{~h}$ p.i. c Host cell proliferation analyzed by estimating cell numbers of

e
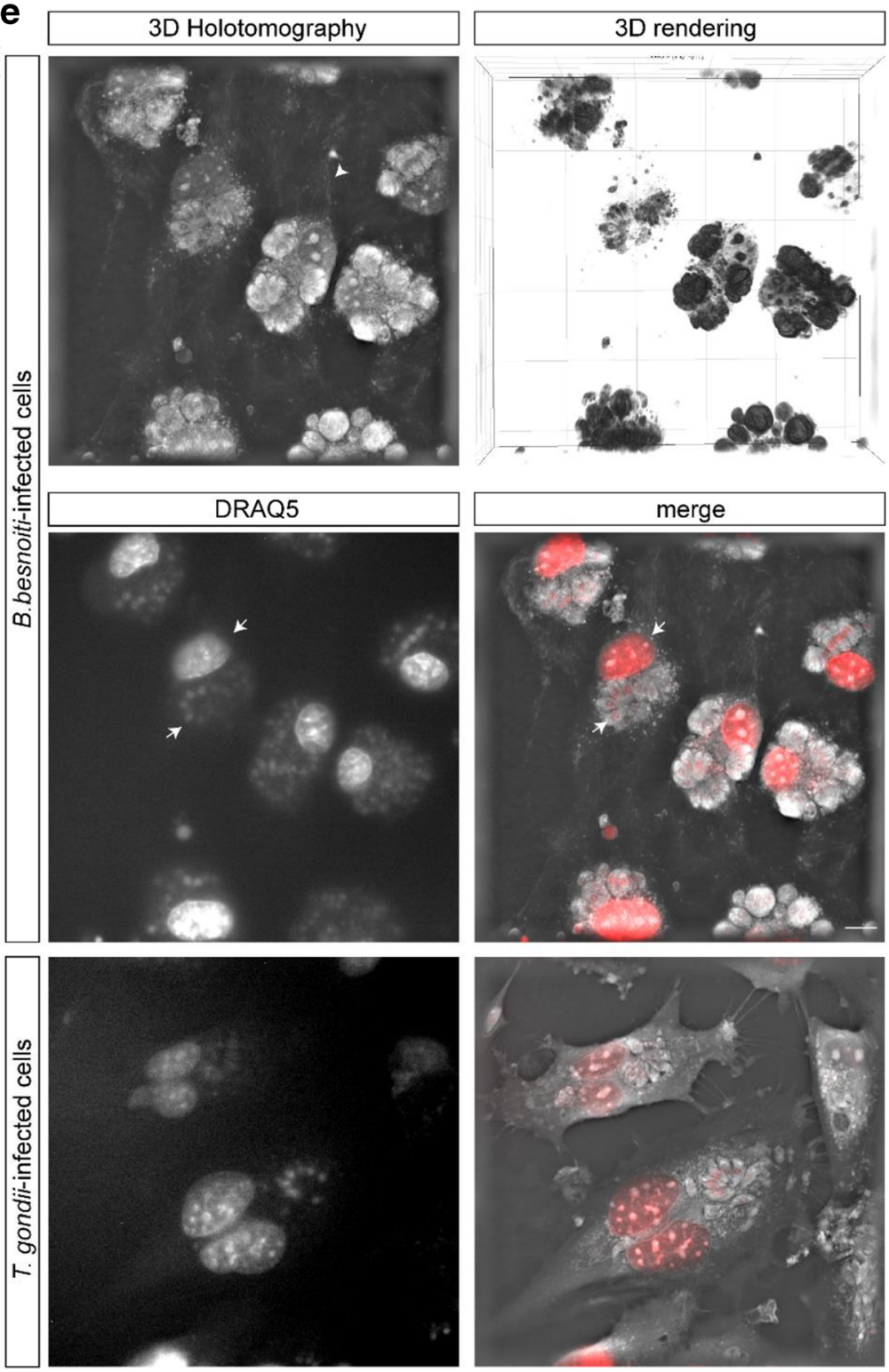

B. besnoiti-infected BUVEC and non-infected controls at 24 h p.i. No statistically significant differences were observed, but it was a hint of decreased number of cells at the $B$. besnoitia-infected monolayer. d Quantification of binucleated host cells in B. besnoiti-infected BUVEC and non-infected controls. e Illustration of DRAQ5 (vital DNA staining, red)-stained host cell nuclei in B. besnoiti- and $T$. gondii-infected BUVEC (24 h p.i.) via 3D holotomographic microscopy (note: binucleated phenotype in case of $T$. gondii-infected BUVEC)

different parameters between BUVEC isolates in different experimental set-ups had been observed before, and, thus, we made efforts to interpret the variation on a case by case basis (Conejeros et al. 2019; Taubert et al. 2016).

We recently showed that $T$. gondii infections resulted in a significantly enhanced proportion of BUVEC presenting more than one nucleus (mainly binucleated BUVEC; Velásquez et al. 2019). For comparative reasons, we here also estimated the cell nucleus numbers in B. besnoiti-infected BUVEC and non-infected controls. Our results showed that $B$. besnoiti infections had no effect on host cell nucleus numbers (Fig. 1d). This was also tested via DRAQ5 (vital staining of nuclei)based live cell 3D holotomographic microscopy (3D Nanolive $\left.{ }^{\circledR}\right)$. By this novel live cell imaging technique, we showed that $B$. besnoiti infections did not affect the nuclear phenotype, while $T$. gondii infections, which were used for 
comparative reasons, indeed induced a binucleated phenotype in BUVEC (Fig. 1e).

\section{B. besnoiti induces host cell stasis at G1-to-S-phase transition}

To estimate whether $B$. besnoiti infections dysregulate host cellular cell cycle progression in BUVEC, we performed flow cytometry-based analyses on the cellular DNA content. This well-established method simply measures cellular DNA abundance, thereby allowing for the discrimination of the three main periods of the cell cycle (G0/G1-; S-; G2/M-phase). Even though this technique lacks high sensitivity, we could recently demonstrate a $T$. gondii-driven shift of cell cycle phases in BUVEC by applying this method (Velásquez et al. 2019). Here, the analysis was performed on BUVEC population in the SSC-H vs FSC-H graph (exemplary illustration in Fig. 2a), where we selected the three main peaks representing the three main phases of the cell cycle (G0/G1-; S-; G2/M-phase). However, by comparing total cell layers of $B$. besnoiti-infected BUVEC with non-infected ones, we could not identify any influence of $B$. besnoiti infections on host cell cycle progress (Fig. 2b). Nevertheless, the G1-phase of infected cells seemed to be higher in comparison with the non-infected monolayer. On account of this, we analyzed G0/ G1-phase in more detail (Fig. 2c).We conducted a correlation between the value of each BUVEC isolate in the non-infected condition in comparison with the value of the same isolate, but in the B. besnoitia-infected layer. The results showed that $4 / 6$ isolates revealed an increased number of cells in the G0/G1phase (isolates 1-3, 5), 1/6 was unchanged (isolate 4), and 1/6 showed a decrease in the percentage of cells in G0/G1 (isolate

a

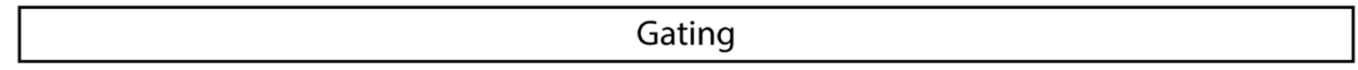

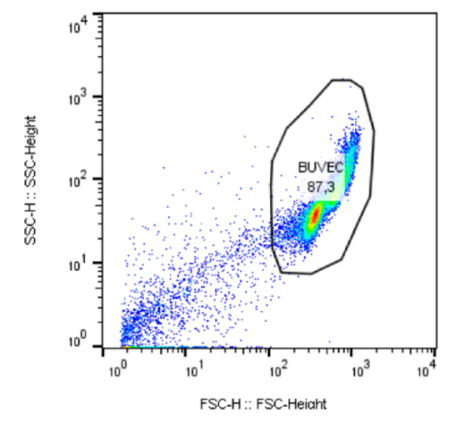

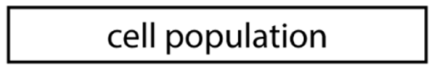

b

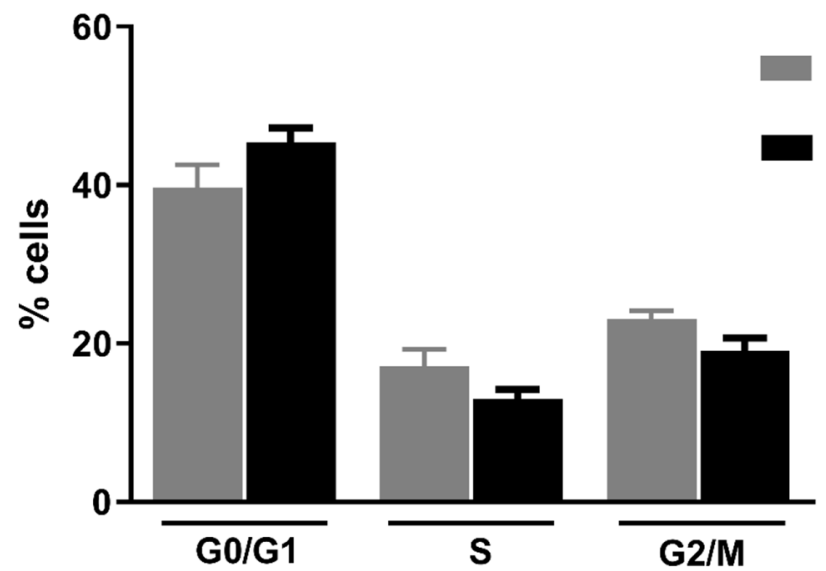

C

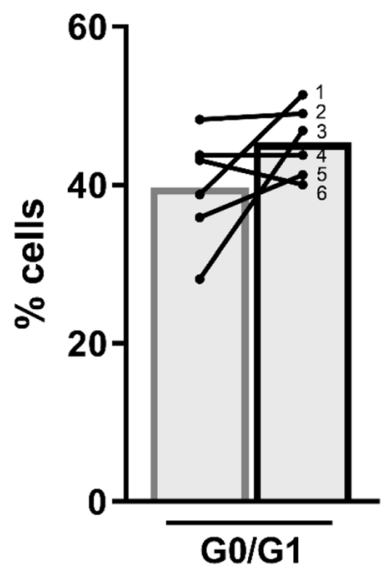

Fig. 2 Distribution of cell cycle phases in B. besnoiti-infected BUVEC. BUVEC were infected with $B$. besnoiti and examined for DNA content at 24 h p.i. by FACS-based analyses. a Flowchart of the FACS analysis showing the total number of cells in G- (one genomic DNA copy), G2(two genomic copies), and S- (the cell population in between both phases) phase. The cells were first gated to eliminate debris from the analysis. Furthermore, the DNA channel vs the population histograme was used to get the total number of cells in each peak. b Mean data obtained from B. besnoiti-infected BUVEC $(n=6)$, plotted as a percentage of the total cells vs DNA amount. Bars represent the median \pm SD. c G1-phase graph from (b) comparing the BUVEC isolates distribution between non-infected and B. besnoiti-infected cells. Light increase in the number of cells was observed in the peak corresponding to $\mathrm{G} 0 / \mathrm{G} 1$; however, the value was not statistically significant 


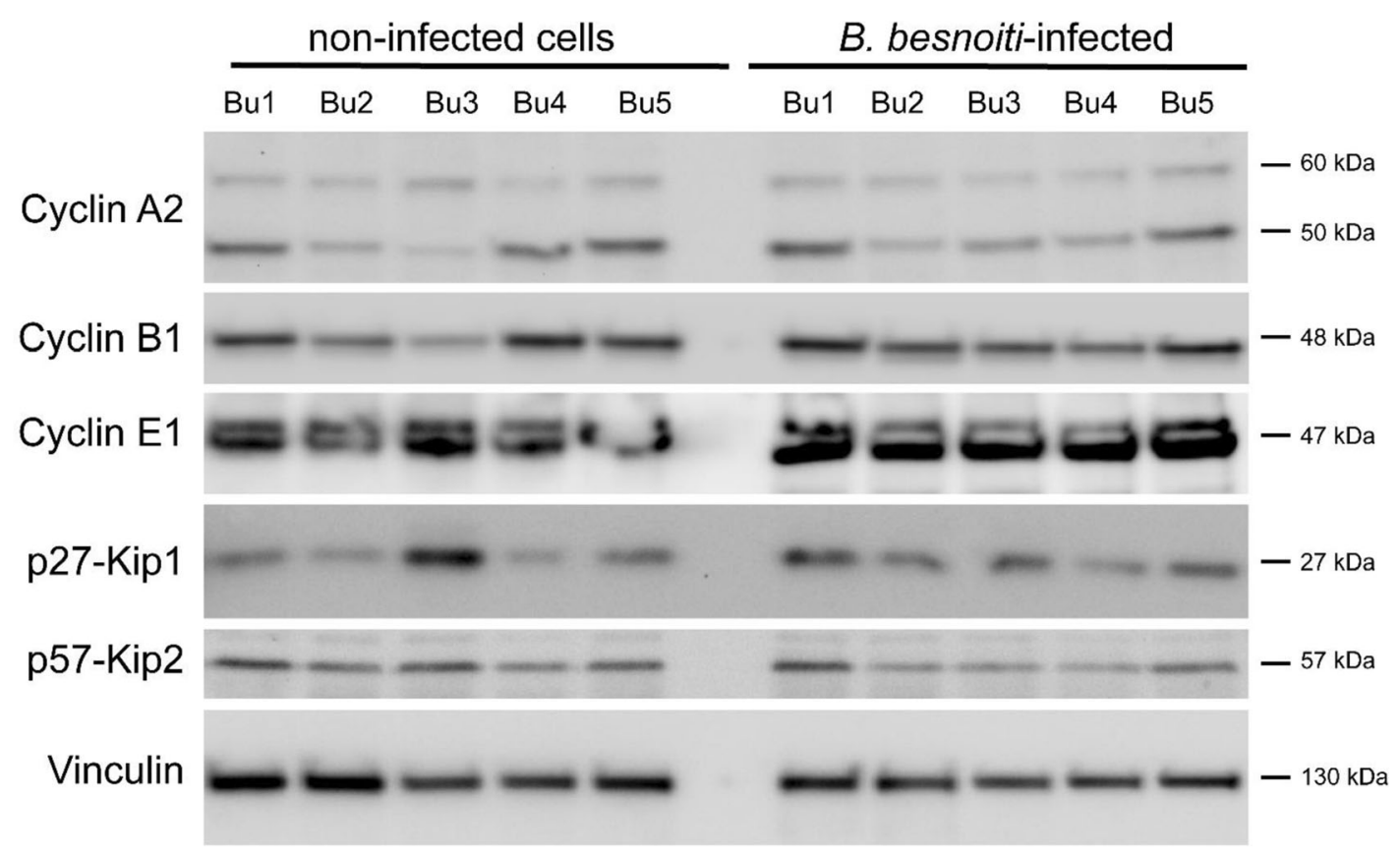

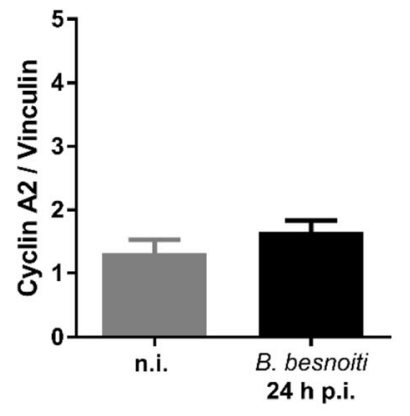

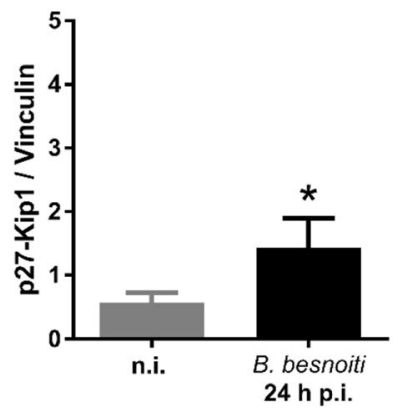

Fig. 3 Analysis of cell cycle-related molecule expression in $B$. besnoitia-infected BUVEC. a Five biological replicates of BUVEC were infected with $B$. besnoiti tachyzoites and analyzed by western blotting for the abundance of the cell cycle-related molecules cyclin A2, cyclin B1, cyclin E, p27-Kip1, and p57-Kip2 at $24 \mathrm{~h}$ p.i. The density of

6). Given that analyses based on rough cellular DNA content may not be sensitive enough to detect minor changes in cell cycle progression, we additionally controlled $B$. besnoiti-infected BUVEC for protein abundance of several key molecules regulating cell cycle phases. Thus, cyclin B1 (indicative for G2 to M-phase transition), cyclin E1 (indicative for G1/S phase
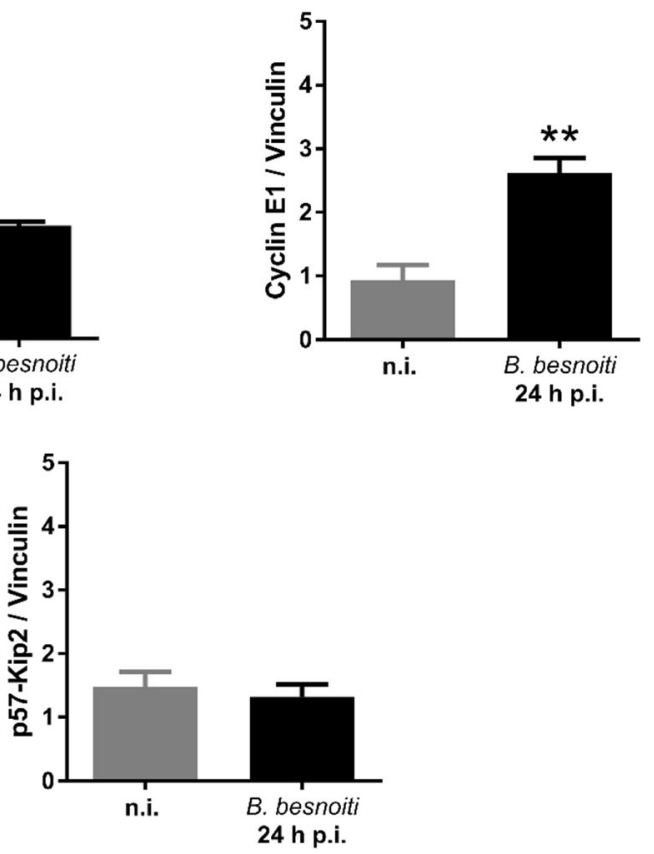

the protein signals was quantified, and graphed as a relative ratio to vinculin (housekeeping protein). Cyclin E1 and p27-kip1 were upregulated in infected cells thereby indicating a G0/G1 cell cycle arrest. Bars represent the median $\pm \mathrm{SD}$ of five biological replicates

transition), and cyclin A2 (indicative for S/G2-phases transition) were controlled for expression via western blotting. Furthermore, p27-kip1 and p57-kip2 (inhibitors of G1-S transition cyclins) were analyzed in their abundance to control for a potential cell cycle arrest. Given that primary BUVEC monolayers vary considerably in their individual reactions, we here included five 

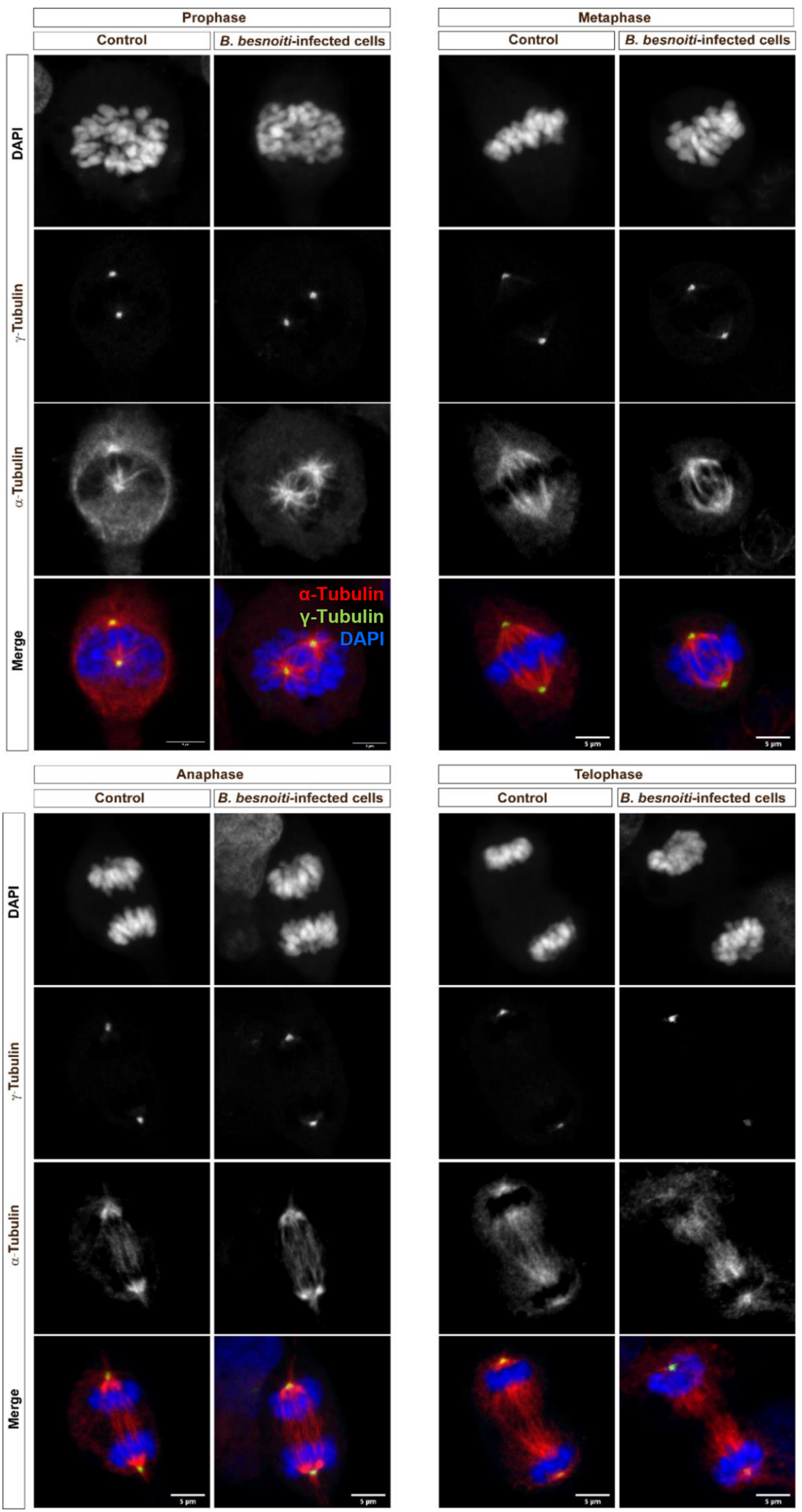
Fig. 4 Exemplary illustration of chromosome segregation and mitotic spindle formation in mitotic $B$. besnoiti-infected BUVEC. Mitotic $B$. besnoiti-infected BUVEC and non-infected cells were stained with anti-pHH3 S10 (green) for chromosome detection, with anti- $\alpha$-Tubulin (red) for mitotic spindle detection. Pictures were taken as a confocal series (z-stack) via confocal microscopy and lately processed as flat images using the ImageJ software (z-projection). The mitotic spindle structure at each cell cycle phase demonstrated that $B$. besnoiti is not intefering with the mitosis process of the host cell. Scale bar represents $5 \mu \mathrm{m}$

different BUVEC isolates. Western blotting analyses revealed cyclin E1 to be significantly enhanced in its abundance in $B$. besnoiti-infected BUVEC when compared with noninfected control cells ( $p=0.00314$; Fig. 3). Due to a technical problem in the BUVEC isolate number 5 , the measurements from the non-infected and the $B$. besnoitia-infected cells were erased from the statistical analysis. No significant changes were detected for cyclin A2 or cyclin B1, suggesting that neither G2 phase nor mitosis was affected by $B$. besnoiti infections. In contrast to p57-Kip2, we furthermore detected a significant increase of p27-Kip1 abundance in B. besnoiti-infected BUVEC (infected vs control cells, $p<0,0379$; Fig. 3). This regulative molecule is a cyclin-CDK inhibitor blocking cyclin E-CDK2 complex activation. Overall, current expression profiles suggested that $B$. besnoiti-infected cells experienced a stasis at G1to-S phase transition.

\section{B. besnoiti infections alter neither chromosome condensation nor mitotic spindle formation in BUVEC}

Since we recently showed that mitosis was impaired on the level of chromosome condensation and mitotic spindle formation in $T$. gondii infections in BUVEC (Velásquez et al. 2019), and since the parasite may modulate host cell cycle on different functional levels, we additionally controlled whether $B$. besnoiti infections may also modulate mitosis progression. Correspondingly, both non-infected and $B$. besnoiti-infected BUVEC were stained for chromosomes (DAPI), microtubules forming the mitotic spindle ( $\gamma$-tubulin), and for centrosomes ( $\gamma$-tubulin). In total, 100 cells were analyzed for each condition. Confocal microscopic analyses revealed that $B$. besnoiti infections neither affected chromosome condensation nor mitotic spindle formation during mitosis (Fig. 4). As such, following chromosome arrangement in infected mitotic host cells, we detected normal segregation of chromosomes in
Fig. 5 Analysis of phosphorylated-histone $\mathrm{H} 3$ and PCNA expression in B. besnoitia-infected BUVEC. a Five biological replicates of BUVEC were infected with $B$. besnoiti tachyzoites and analyzed by western blotting for phosphorylated histone $\mathrm{H} 3$ (S10) and PCNA expression at $24 \mathrm{~h}$ p.i. The density of the protein signals was quantified and graphed as a relative ratio to vinculin as housekeeping protein. Both proteins were upregulated, but only p-HH3S10 was statistically significant. Bars represent the median $\pm \mathrm{SD}$ from five biological replicates. $* *=p<0.0741$
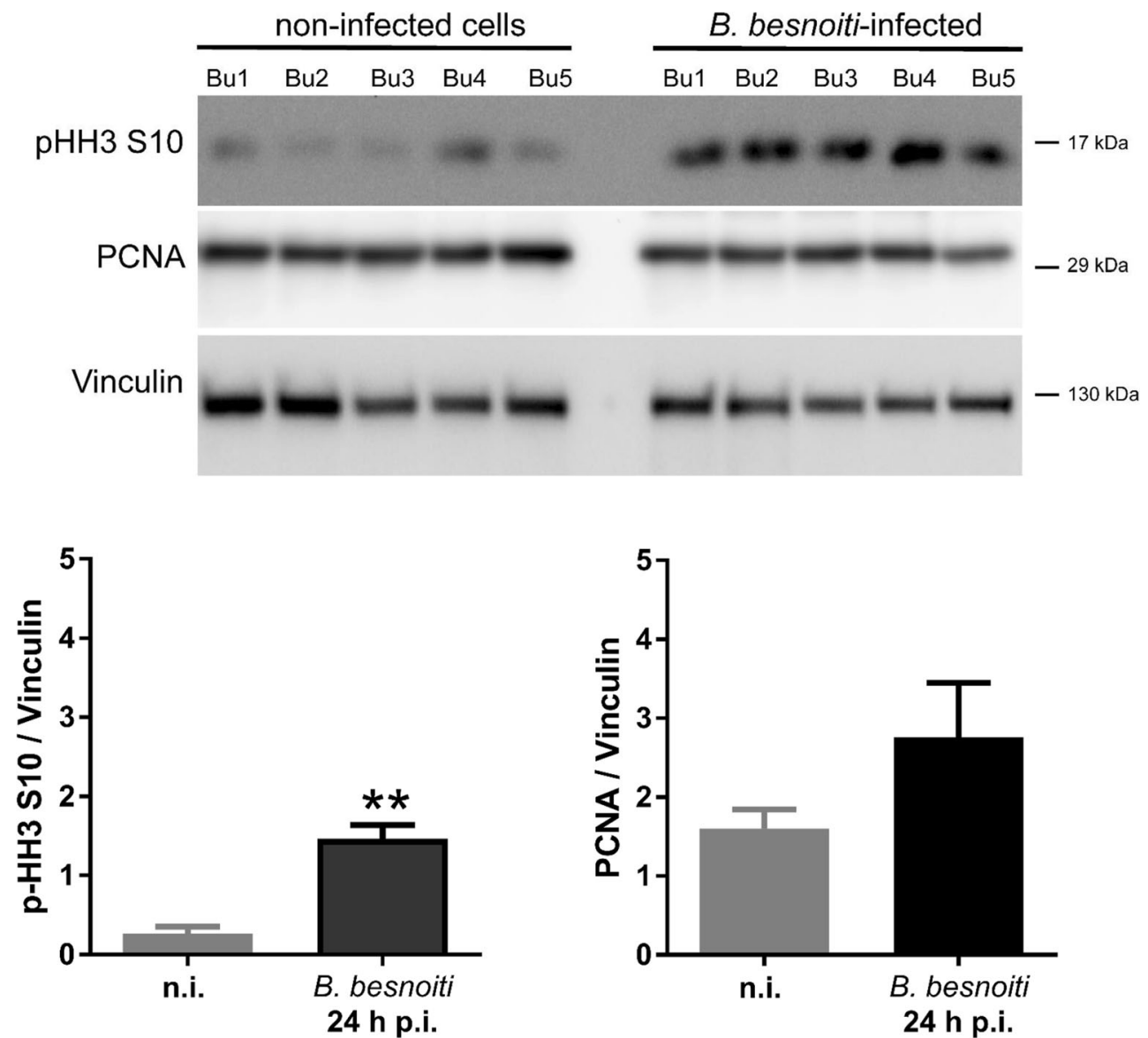

24 h p.i. 
prophase, metaphase, anaphase, and telophase (Fig. 4blue). Likewise, the formation and migration of the tubulin-based cytoskeleton corresponded well to the mitotic spindle shape in control cells for each step (Fig. 4red). Furthermore, no changes were detected in cases of centrosome formation and localization in mitotic stages (Fig. 4-green). However, when estimating the abundance of phosphorylated histone H3 (Ser10; a classical chromosome condensation marker), a significantly higher expression level of this protein was found in B. besnoiti-infected BUVEC when compared with that of control cells (infected vs control cells, $p<0,0017$; Fig. 5).

\section{B. besnoiti infection induces an increase in nuclear PCNA abundance}

Proliferating cell nuclear antigen (PCNA) is critically involved in DNA replication and repair, and has cell cycledependent properties. PCNA nuclear distribution is characteristic for $\mathrm{G}$ phase, early, mid-, and late $\mathrm{S}$ phase, and is therefore often used as a marker for sub-stages of DNA replication (Schönenberger et al. 2015). Given that B. besnoiti-infected cells seemed to be arrested at G1/S transition, we here analyzed S-phase progression by estimating PCNA localization and nuclear/cytoplasmic abundance. When comparing total PCNA expression in B. besnoiti-infected host cells and noninfected BUVEC layers via western blotting at $24 \mathrm{~h}$ p.i., no significant differences could be identified, indicating that not total PCNA abundance was not changed (Fig. 5). Given that tachyzoites exclusively reside in the cytoplasmic compartment, parasite-derived signals could falsify these data. We then separated nuclear and cytosolic fractions from both non-infected and B. besnoiti-infected host cells ( $24 \mathrm{~h}$ p.i.) for western blot analyses. The purity of each extract was confirmed by the detection of typical cytosolic ( $\alpha$-tubulin) or nuclear (lamin B1) proteins. As expected, PCNA was mainly expressed in the nuclear fraction when compared with cytosolic extracts. In line with our observations described above, the nuclear PCNA abundance in B. besnoiti-infected cells was enhanced in nuclear extracts (which are devoid of parasites) (Fig. 6); however, this was not statistically significant (infected vs non-infected cells, $p=0.1615$ ). Neither total nor nuclear PCNA abundance showed significant differences when analyzed by WB at $24 \mathrm{~h}$ p.i. However, by confocal microscopy, a time-dependent increase of nuclear PCNA abundance with a maximum at $12 \mathrm{~h}$ p.i. was observed (Fig. 7). We estimated the nuclear PCNA abundance during $24 \mathrm{~h}$ of in vitro infection using immunostaining (Fig. 7) and calculated PCNA signal intensity relative to the host cell nucleus (DAPI signal). In total, 300 cells were analyzed for each condition. B. besnoiti-infected cells showed a transient peak at $12 \mathrm{~h}$ p.i. (Fig. 7b, infected vs non-infected cells, at all-time points tested, $p<0.0001$ ), decreasing after 18 h p.i. The nuclear
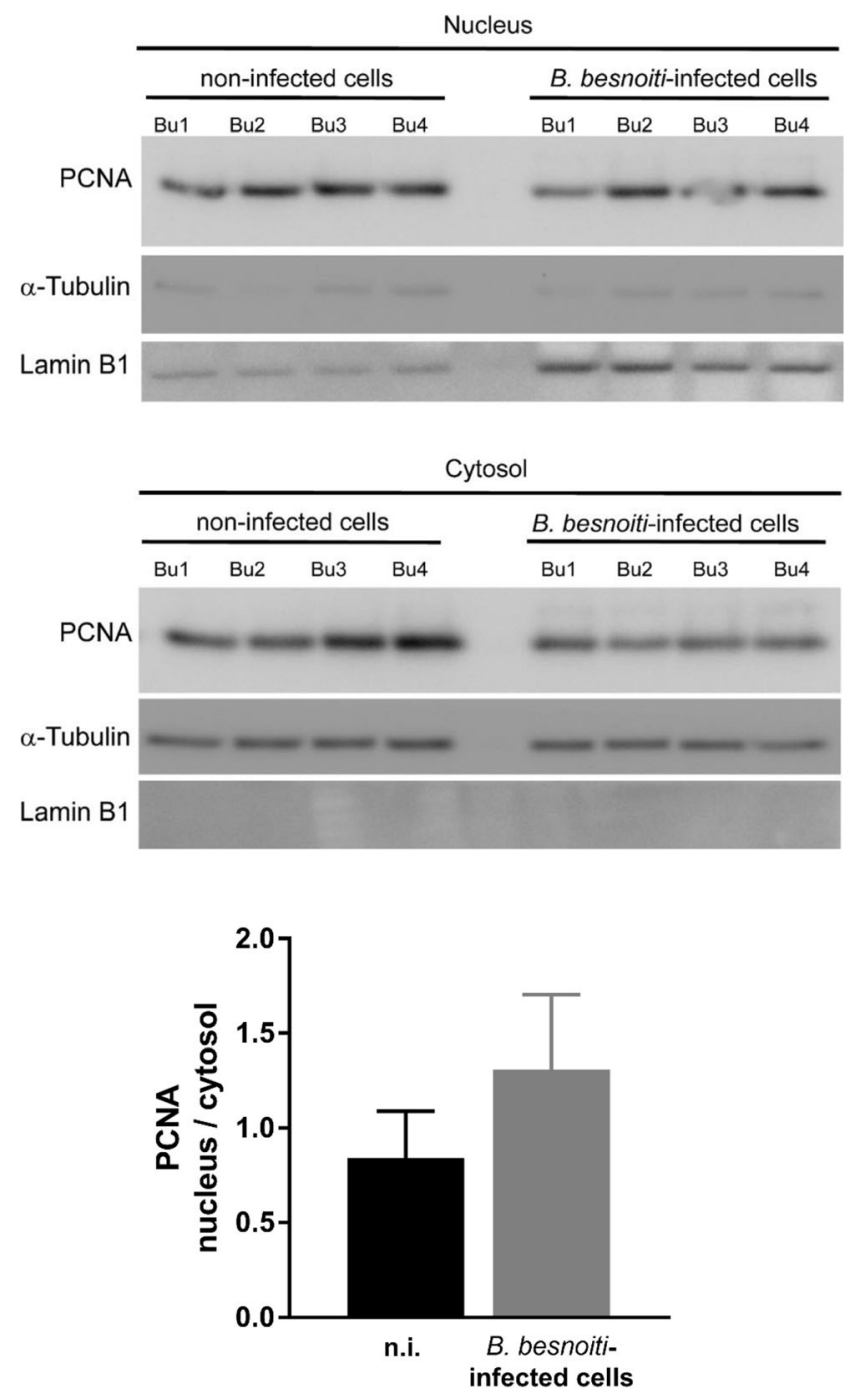

Fig. 6 PCNA abundance in nuclear and cytosolic protein extracts of $B$. besnoiti-infected BUVEC. Nuclear and cytosolic protein extracts from four biological replicates of $B$. besnoiti-infected BUVEC and controls cells were subjected to western blotting to quantify PCNA expression. For control of nuclear and cytosolic fraction purity, the abundance of $\alpha$-tubulin (typical cytosolic protein) and lamin B1 (typical nuclear protein) was analyzed. The density of the protein signals was quantified and graphed as relative ratios: PCNA vs Lamin B1 for nuclear extracts and PCNA vs $\alpha$-tubulin for cytosolic extracts. The ratio of $\mathrm{PCNA} /$ vinculin showed higher values in comparison with the cytosolic one; however, it was not statistically significant. Bars represent the median \pm SD from five biological replicates

PCNA localization showed the characteristic pattern for a G1-phase (Fig. 7a).

\section{Discussion}

$B$. besnoiti belongs to the apicomplexan cyst-forming protozoan Sarcocystidae family. During the acute phase of bovine 
Fig. 7 Exemplary illustration of PCNA distribution in

B. besnoiti-infected BUVEC. a

B. besnoiti-infected BUVEC and control cells were stained for

DNA (DAPI, blue), B. besnoiti tachyzoites (in-house antiserum, red) and for PCNA (green) and analyzed via confocal microscopy. b Measurements of nuclear PCNA-related signals in relation to total cell-derived signals during in vitro infection (4-24 h p.i.). The insets in $24 \mathrm{~h}$ p.i. pictures represent PCNA localization in the non-infected cells nuclei at the same time. The PCNA signal showed a peak at $12 \mathrm{~h}$ p.i., been progressively decreased after $18 \mathrm{~h}$ p.i. Scale bar represents $5 \mu \mathrm{m}$. Asterisks: surface PCNA localization in B. besnoiti tachyzoites. White arrows: PCNA signal in the nuclear compartment. Bars represent the median \pm SD against the non-infected cells control. $* * * *=$ $p<0.0001$ a

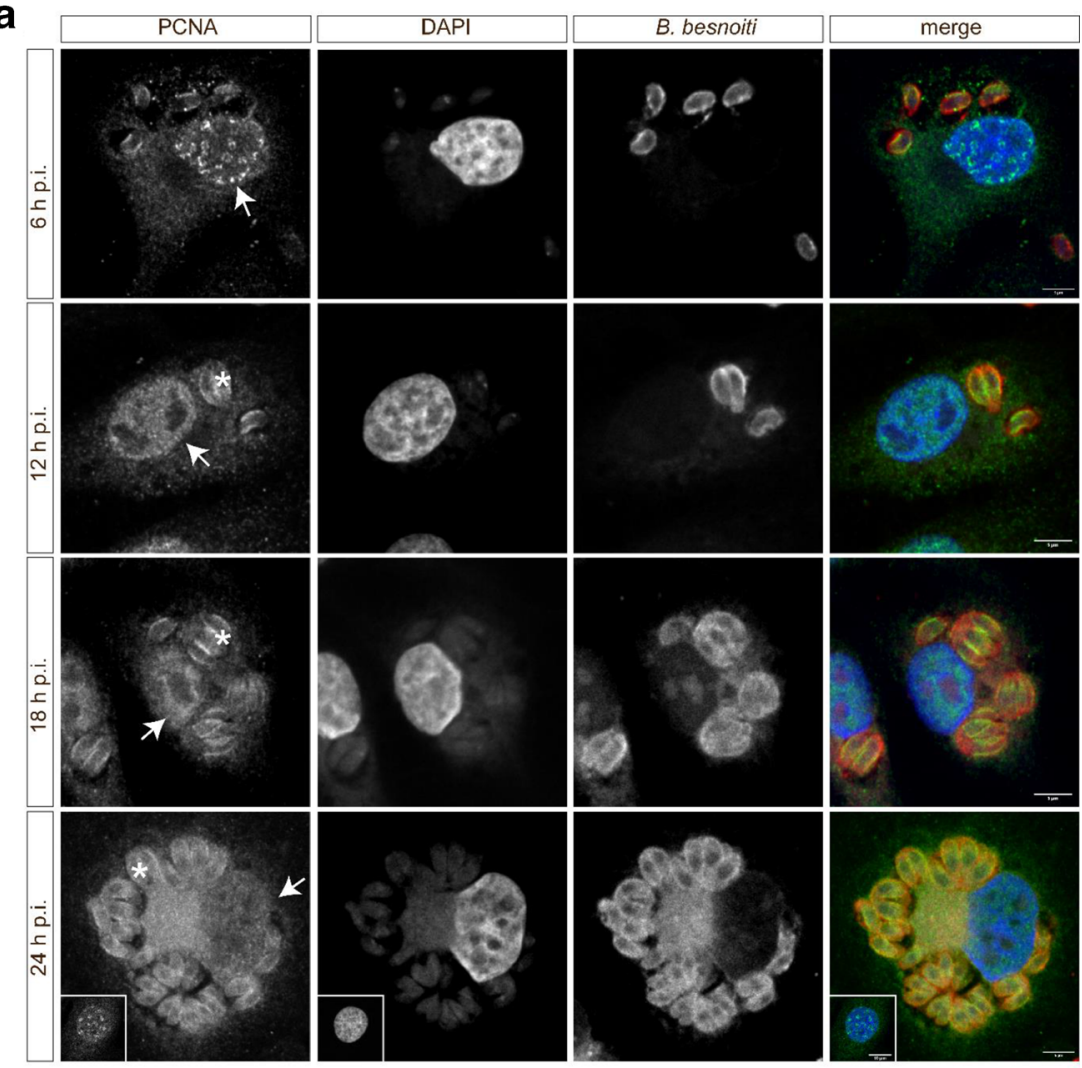

b

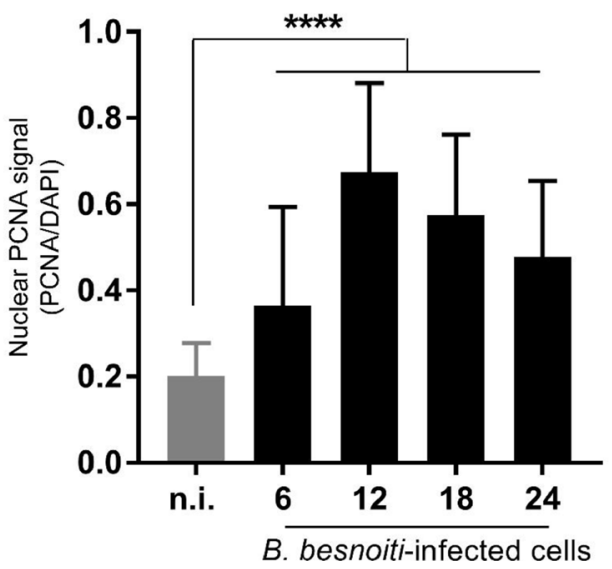

in vitro primary host cell system (bovine umbilical vein endothelial cells) under identical culture conditions, thereby standardizing experimental conditions. Using this approach, we here showed that $B$. besnoiti indeed differentially modulates host endothelial cellular cell cycle when compared with $T$. gondii and affects $\mathrm{G} 1 / \mathrm{S}$ transition and related molecules in a species-specific manner.

B. besnoiti infections affect cattle as intermediate hosts and, as stated above, endothelial host cells of vessels represent the main host cells being infected during acute phase of infection (Basson et al. 1970; Bigalke 1981). In order to be rather close to the in vivo situation and to allow a direct comparison with

T. gondii infections (Velasquez et al. 2019) by using the same 
recently published $T$. gondii data (Velásquez et al. 2019), the current study was performed in a primary bovine endothelial cell type. Furthermore, by using a primary host cell type, false influences on host cellular cell cycle progression or cell division activities driven by cell immortalization or tumoral origin was avoided (Mondello and Chiodi 2013). It is worth noting that we here exclusively analyzed host cell layers for up to $24 \mathrm{~h}$ p.i. to avoid false-negative effects triggered by parasiteinduced host cell lysis. This contrasts to experimental conditions of other studies on coccidian parasites, such as $T$. gondii, in which host cell proliferation was estimated for up to $48 \mathrm{~h}$ p.i. or even $120 \mathrm{~h}$ p.i. (Brunet et al. 2008).

By microscopical means, we confirmed that bovine endothelial cells (BUVEC) allowed full intracellular merogony development and resulted in the release of mature and motile $B$. besnoiti tachyzoites. Given that individual primary endothelial cell isolates generally show high inter-donor variability (Joyce 2003; Zhu and Joyce 2004), we here always included at least five BUVEC isolates in each experimental setting. Consequently, we assume that observed differences in host cell modulation in the current study are indeed realistic.

By estimating total BUVEC numbers at $24 \mathrm{~h}$ p.i., we showed that $B$. besnoiti infections do not influence host cell proliferation. This finding contrasts with data on $T$. gondii infections which were reported either to dampen host cell proliferation in non-endothelial cell types (Brunet et al. 2008; Molestina et al. 2008; Kim et al. 2016) or to trigger proliferation in the same endothelial cell type we used (Velásquez et al. 2019). Accordingly, we could also not state an infection-driven increase of bi- or multi-nucleated host cells as previously reported for $T$. gondii infections (Velásquez et al. 2019). In this respect, the combination of DRAQ5 staining with live cell 3D-holotomographic microscopy easily allowed nuclear phenotype estimation and nicely illustrated B. besnoiti development in BUVEC.

In contrast to $T$. gondii-related cell cycle data (Velásquez et al. 2019), FACS-based quantification of cellular DNA contents did not reveal B. besnoiti-driven changes in cell cycle phase patterns when compared with non-infected host cells. This may be based on different reasons: (i) this method is not sensitive enough to detect moderate changes in cell cycle phases, and (ii) when analyzing infected cell layers, this method (which merely estimates crude DNA abundance) cannot distinguish between host cell- and parasite-derived DNA. Given that we achieved a rather high infection rate with several meronts per host cell (2-20, which is typical for endothelial $B$. besnoiti infections in the current experimental set-up), the merge of parasite- and host cell-derived reactions may have masked alterations in host cellular cell cycle phases. Nonetheless, analysis of cell cycle-related molecules involved in regulation revealed cyclin E1 (one of the main regulatory protein of G1-phase and G1-to-S-phase progression) to be selectively upregulated in B. besnoiti-infected cell layers since other cyclins (cyclin A2, cyclin B1, or the regulatory molecule p57-kip2) did not show any altered abundance. Cyclin E1 represents an activator of cyclin-dependent kinase (CDK) 2, accumulates at G1/S boundary of cell cycle, and stimulates entry into and progression through $\mathrm{S}$ phase (Sauer and Lehner 1995; Ohtsubo et al. 1995; Ekholm and Reed 2000). In somatic mammalian cells, cyclin E1 levels typically decline during $\mathrm{S}$ phase, thereby reaching low or undetectable levels by the time replication is completed (Ekholm et al. 2001). Thus, an enhancement or accumulation of cyclin $E$ indicates that $B$. besnoiti infection either triggers cyclin E1 expression or blocks its degradation, which both affect the cellular exit from G1-phase. Another interesting finding was the upregulation of p27-kip1, a CDK inhibitor belonging to the Cip/Kip family. The main regulation of p27-kip1 is mediated by proteolysis via ubiquitin/protease pathway at the $\mathrm{G} 1 / \mathrm{S}$ boundary (Lisztwan et al. 1998). This process is closely related with cyclin E1-CDK2 complex activity, which modulates p27-kip1 phosphorylation and allows its entrance into the ubiquitination pathway. Cells can only enter into S-phase when p27-kip1 proteolysis is completed. Thus, the current data suggested that $B$. besnoiti infection affected proper cyclin E1-CDK formation or activation which directly interferes with p27-kip1 proteolysis and is concomitant with G1-phase arrest. The finding of $B$. besnoiti-driven $\mathrm{G} 1 / \mathrm{S}$ arrest was revealed as species-specific since $T$. gondii infections triggered stasis of BUVEC in (G2/)M-phase (Velásquez et al. 2019). Furthermore, records on $T$. gondii-driven cell cycle impairment in non-endothelial cells reported an infection-driven shift from G0/G1- to S-phase (Molestina et al. 2008; Lavine and Arrizabalaga 2009) or a host cellular arrest in G2-phase (Brunet et al. 2008), thereby most probably indicating cell type-specific reactions.

G1 phase is followed by S-phase, which signifies the step during which cells duplicate their genome for daughter cell formation. PCNA, which is involved in DNA replication, has cell cycle-dependent properties and typically localizes to nuclear sites of active replication during S-phase (Bravo and Celis 1985; Celis and Celis 1985a; Essers et al. 2005; Sugimoto 2015). Thus, precise PCNA nuclear distribution is used to discriminate sub-stages of S phase (early, mid, and late S phase) (Bravo and Celis, 1985; Celis and Celis 1985a, b; Ersoy et al. 2009). Given that the current data indicated a $B$. besnoiti induced at $\mathrm{G} 1 / \mathrm{S}$ transition and assuming that multiple phases may be targeted by the parasite, we here analyzed subcellular PCNA abundance and distribution in B. besnoitiinfected BUVEC. One interesting finding, was that host cellular PCNA distribution changed throughout in vitro merogony, showing that even when PCNA was located in the nuclear compartment, it showed a typical pattern of G1phase after $18 \mathrm{~h}$ p.i. (homogeneous distribution in the nucleus). Nevertheless, quantification of nuclear PCNA signals revealed an increase of PCNA abundance during $B$. besnoiti 
infection in BUVEC peaking at $12 \mathrm{~h}$ p.i., which was the last point in time when some S-phase typical pattern could be observed. Correspondingly, when preparing nuclear and cytoplasmic extracts from $B$. besnoiti-infected BUVEC for western blot-derived expression analyses, an increase of PCNA abundance was observed in infected BUVEC. Overall, these data suggest that $B$. besnoiti induces a G1 arrest in a timedependent manner, thereby hampering host cells to enter into S-phase.

Emerging data on chromosome formation suggest that whenever chromosomes fail to properly replicate in S-phase, subsequent segregation of sister chromatids during mitosis will be impaired as well (Mankouri et al. 2013). For this reason and in order to compare $B$. besnoiti-driven reactions with T. gondii-related ones, we here also analyzed host cellular chromosome segregation, i.e., a cellular process that is highly regulated and requires numerous factors for adequate processing, such as molecules mediating DNA movement, DNA linkage to cellular structures, and chromosome maintenance (Duro and Marston 2015). Obviously, proper mitotic spindle formation, being based on tubulin-derived structures for chromosome cell linkage (Inoué and Salmon 1995; Inoué 1997; Rieder and Khodjakov 2003), is also fundamental for adequate chromosome segregation. Recently, we showed that T. gondii infection of BUVEC highly interferes with these processes and leads to chromosome missegregation and mitotic spindle impairment (Velásquez et al. 2019). However, B. besnoiti-infected BUVEC showed normal chromosome structures and mitotic spindle formation, and no impairment of these processes could be stated, thereby indicating speciesspecific effects (once) again. Even though the mitotic process did not seem to be affected in $B$. besnoiti infections, analyses on phosphorylated histone H3 (S10) showed a significantly enhanced abundance in B. besnoiti-infected host cells. To date, two functions have been assigned to serine 10 phosphorylation of histone $\mathrm{H} 3$ with one being related to chromosome condensation and the other being linked to distinct gene transcription activation (Prigent and Dimitrov 2003). In both cases, the serine phosphorylation-mediating kinase appears fundamental (Schmitt et al. 2002; Taylor 1982; DeManno et al. 1999; Cheung et al. 2000; Hans and Dimitrov, 2001). This process selectively occurs in some specific genome regions, depending on the stimuli that the cell received. It has been previously identified that only some subsets of genes are altered; one of these is related with the inflammatory response triggered by cytokines (Saccani et al. 2002). To date, distinct cytokine responses are well-known for $T$. gondii and P. falciparum infections (Baker et al. 2008; Fischer et al. 1997), and inflammatory responses were also described for $B$. besnoiti infections in BUVEC, thereby allowing us to hypothesize that an increase of $\mathrm{HH} 3 \mathrm{~S} 10$ phosphorylation driven by $B$. besnoiti infection may also be explained by the inflammatory response triggered by the parasite.
In conclusion, we here showed that $B$. besnoiti tachyzoite infection indeed affects host endothelial cell cycle progression in a species-specific manner and avoids host cell cycle progression by a G1-phase arrest. Further research will elucidate the precise mechanisms, signaling pathways, and molecules which are involved in this complex process.

Acknowledgments Authors thank A. Wehrend (Clinic for Obstetrics, Gynecology, and Andrology of Large and Small Animals, Justus Liebig University Giessen, Giessen, Germany) for the continuous supply of bovine umbilical cords. Dr. Kalus Deckmann (Institut für Anatomy und Zellbiologie, Justus Liebig Universität Giessen, Giessen, Germany) for providing free access to a Zeiss LSM 710 confocal microscope. We are grateful to Hannah Salecker for her valuable work in primary host cell isolation as well as parasite maintenance.

Author contributions ZDV and AT planned and designed the experiments. ZDV, SLO, and LPO performed the experiments. FACS reading and analysis: ZDV, LPO, and SH. ZDV, SLO, CH, and AT performed analyses and interpretation of the data. All authors prepared, revised, and approved the final version of the manuscript.

Funding Information Open Access funding provided by Projekt DEAL.

\section{Compliance with ethical standards}

Competing interests The authors declare that they have no competing interests.

Open Access This article is licensed under a Creative Commons Attribution 4.0 International License, which permits use, sharing, adaptation, distribution and reproduction in any medium or format, as long as you give appropriate credit to the original author(s) and the source, provide a link to the Creative Commons licence, and indicate if changes were made. The images or other third party material in this article are included in the article's Creative Commons licence, unless indicated otherwise in a credit line to the material. If material is not included in the article's Creative Commons licence and your intended use is not permitted by statutory regulation or exceeds the permitted use, you will need to obtain permission directly from the copyright holder. To view a copy of this licence, visit http://creativecommons.org/licenses/by/4.0/.

\section{References}

Baker VS, Imade GE, Molta NB, Tawde P, Pam SD, Obadofin MO, Sagay SA, Egah DZ, Iya D, Afolabi BB, Baker M, Ford K, Ford R, Roux KH, Keller TCS, III (2008) Cytokine-associated neutrophil extracellular traps and antinuclear antibodies in Plasmodium falciparum infected children under six years of age Malar J 7:41

Basson PA, McCully RM, Bigalke RD (1970) Observations on the pathogenesis of bovine and antelope strains of Besnoitia besnoiti (Marotel, 1912) infection in cattle and rabbits

Bigalke RD (1981) Besnoitiosis and Globidiosis. In: Ristic M, McIntyre I (eds) Diseases of cattle in the tropics: economic and zoonotic relevance. Springer Netherlands, Dordrecht, pp 429-442

Bravo R, Celis JE (1985) Changes in the nuclear distribution of cyclin (PCNA) during S-phase are not triggered by post-translational modifications that are expected to moderately affect its charge. FEBS Lett 182:435-440 
Brunet J, Pfaff AW, Abidi A, Unoki M, Nakamura Y, Guinard M, Klein JP, Candolfi E, Mousli M (2008) Toxoplasma gondii exploits UHRF1 and induces host cell cycle arrest at G2 to enable its proliferation. Cell Microbiol 10:908-920. https://doi.org/10.1111/j.14625822.2007.01093.x

Celis JE, Celis A (1985a) Individual nuclei in polykaryons can control cyclin distribution and DNA synthesis. EMBO J 4:1187-1192. https://doi.org/10.1002/j.1460-2075.1985.tb03758.x

Celis JE, Celis A (1985b) Cell cycle-dependent variations in the distribution of the nuclear protein cyclin proliferating cell nuclear antigen in cultured cells: subdivision of S phase. Proc Natl Acad Sci U S A 82: 3262-3266

Cheung P, Allis CD, Sassone-Corsi P (2000) Signaling to chromatin through histone modifications. Cell 103:263-271. https://doi.org/ 10.1016/S0092-8674(00)00118-5

Conejeros I, Velásquez ZD, Grob D, Zhou E, Salecker H, Hermosilla C, Taubert A (2019) Histone H2A and bovine neutrophil extracellular traps induce damage of Besnoitia besnoiti-infected host endothelial cells but fail to affect total parasite proliferation. Biology 8:78. https://doi.org/10.3390/biology8040078

Cortes HCE, Mueller N, Esposito M et al (2007) In vitro efficacy of nitroand bromo-thiazolyl-salicylamide compounds (thiazolides) against Besnoitia besnoiti infection in Vero cells. Parasitology 134:975985. https://doi.org/10.1017/S0031182007002417

Cortes H, Leitão A, Gottstein B, Hemphill A (2014) A review on bovine besnoitiosis: a disease with economic impact in herd health management, caused by Besnoitia besnoiti (Franco and Borges, 1916). Parasitology 141:1406-1417. https://doi.org/10.1017/ S0031182014000262

Costales JA, Daily JP, Burleigh BA (2009) Cytokine-dependent andindependent gene expression changes and cell cycle block revealed in Trypanosoma cruzi-infected host cells by comparative mRNA profiling. BMC Genomics 10:252. https://doi.org/10.1186/14712164-10-252

DeManno DA, Cottom JE, Kline MP et al (1999) Follicle-stimulating hormone promotes histone $\mathrm{H} 3$ phosphorylation on serine-10. Mol Endocrinol 13:91-105. https://doi.org/10.1210/mend.13.1.0222

Dubey JP (2003) Review of Neospora caninum and neosporosis in animals. Korean J Parasitol 41:1-16 2003.41.1.1

Dubey JP, Lindsay DS (1996) A review of Neospora caninum and neosporosis. Vet Parasitol 67:1-59. https://doi.org/10.1016/S03044017(96)01035-7

Duro E, Marston AL (2015) From equator to pole: splitting chromosomes in mitosis and meiosis. Genes Dev 29:109-122. https://doi.org/10. $1101 /$ gad.255554.114

Ekholm SV, Reed SI (2000) Regulation of G1 cyclin-dependent kinases in the mammalian cell cycle. Curr Opin Cell Biol 12:676-684

Ekholm SV, Zickert P, Reed SI, Zetterberg A (2001) Accumulation of cyclin $\mathrm{E}$ is not a prerequisite for passage through the restriction point. Mol Cell Biol 21:3256-3265. https://doi.org/10.1128/MCB. 21.9.3256-3265.2001

Ersoy I, Bunyak F, Chagin V et al (2009) Segmentation and classification of cell cycle phases in fluorescence imaging. Med Image Comput Comput-Assist Interv MICCAI Int Conf Med Image Comput Comput-Assist Interv 12:617-624

Essers J, Theil AF, Baldeyron C et al (2005) Nuclear dynamics of PCNA in DNA replication and repair. Mol Cell Biol 25:9350-9359. https:// doi.org/10.1128/MCB.25.21.9350-9359.2005

Fischer HG, Nitzgen B, Reichmann G, Hadding U (1997) Cytokine responses induced by Toxoplasma gondii in astrocytes and microglial cells. Eur J Immunol 27(6):1539-48

Gollnick NS, Scharr JC, Schares S, Bärwald A, Schares G, Langenmayer MC (2018) Naturally acquired bovine besnoitiosis: disease frequency, risk and outcome in an endemically infected beef herd. Transbound Emerg Dis 65:833-843. https://doi.org/10.1111/tbed.12810
Hans F, Dimitrov S (2001) Histone H3 phosphorylation and cell division. Oncogene 20:3021-3027. https://doi.org/10.1038/sj.onc. 1204326

Hanson KK, March S, Ng S, Bhatia SN, Mota MM (2015) In vitro alterations do not reflect a requirement for host cell cycle progression during Plasmodium liver stage infection. Eukaryot Cell 14:96-103. https://doi.org/10.1128/EC.00166-14

Inoué S (1997) The role of microtubule assembly dynamics in mitotic force generation and functional organization of living cells. J Struct Biol 118:87-93. https://doi.org/10.1006/jsbi.1996.3839

Inoué S, Salmon ED (1995) Force generation by microtubule assembly/ disassembly in mitosis and related movements. Mol Biol Cell 6: $1619-1640$

Joyce NC (2003) Proliferative capacity of the corneal endothelium. Prog Retin Eye Res 22:359-389. https://doi.org/10.1016/S13509462(02)00065-4

Kim MJ, Jung B-K, Cho J et al (2016) Exosomes secreted by Toxoplasma gondii-infected L6 cells: their effects on host cell proliferation and cell cycle changes. Korean J Parasitol 54:147-154. https://doi.org/ 10.3347/kjp.2016.54.2.147

Kuzmenok OI, Chiang S-C, Lin Y-C, Lee ST (2005) Retardation of cell cycle progression of macrophages from G1 to $\mathrm{S}$ phase by ICAM-L from Leishmania. Int J Parasitol 35:1547-1555. https://doi.org/10. 1016/j.ijpara.2005.08.006

Lavine MD, Arrizabalaga G (2009) Induction of mitotic S-phase of host and neighboring cells by toxoplasma gondii enhances parasite invasion. Mol Biochem Parasitol 164:95-99. https://doi.org/10.1016/j. molbiopara.2008.11.014

Lisztwan J, Marti A, Sutterluty H et al (1998) Association of human CUL-1 and ubiquitin-conjugating enzyme CDC34 with the F-box protein $\mathrm{p} 45$ (SKP2): evidence for evolutionary conservation in the subunit composition of the CDC34-SCF pathway. EMBO J 17:368-383

Maksimov P, Hermosilla C, Kleinertz S, Hirzmann J, Taubert A (2016) Besnoitia besnoiti infections activate primary bovine endothelial cells and promote PMN adhesion and NET formation under physiological flow condition. Parasitol Res 115:1991-2001. https://doi. org/10.1007/s00436-016-4941-5

Mankouri HW, Huttner D, Hickson ID (2013) How unfinished business from S-phase affects mitosis and beyond. EMBO J 32:2661-2671. https://doi.org/10.1038/emboj.2013.211

Molestina RE, El-Guendy N, Sinai AP (2008) Infection with Toxoplasma gondii results in dysregulation of the host cell cycle. Cell Microbiol 10:1153-1165. https://doi.org/10.1111/j.1462-5822.2008.01117.x

Mondello C, Chiodi I (2013) Cellular immortalization and neoplastic transformation. Cell Cycle 12:1804-1805. https://doi.org/10.4161/ cc. 24940

Muñoz Caro T, Hermosilla C, Silva LMR, Cortes H, Taubert A (2014) Neutrophil extracellular traps as innate immune reaction against the emerging apicomplexan parasite Besnoitia besnoiti. PLoS One 9: e91415. https://doi.org/10.1371/journal.pone.0091415

Muñoz-Caro T, Silva LMR, Ritter C, Taubert A, Hermosilla C (2014) Besnoitia besnoiti tachyzoites induce monocyte extracellular trap formation. Parasitol Res 113:4189-4197. https://doi.org/10.1007/ s00436-014-4094-3

Ohtsubo M, Theodoras AM, Schumacher J, Roberts JM, Pagano M (1995) Human cyclin E, a nuclear protein essential for the G1-to-S phase transition. Mol Cell Biol 15:2612-2624. https://doi.org/10. 1128/MCB.15.5.2612

Prigent C, Dimitrov S (2003) Phosphorylation of serine 10 in histone H3, what for? J Cell Sci 116:3677-3685. https://doi.org/10.1242/jcs.00735

Rieder CL, Khodjakov A (2003) Mitosis through the microscope: advances in seeing inside live dividing cells. Science 300:91-96. https://doi.org/10.1126/science.1082177

Saccani S, Pantano S, Natoli G (2002) p-38-Dependent marking of inflammatory genes for increased NF-kappa B recruitment. Nat Immunol Sci:69-75 
Samish M, Shkap V, Bin H, Pipano EM (1988) Cultivation of Besnoitia besnoiti in four tick cell lines. Int J Parasitol 18:291-296

Sauer K, Lehner CF (1995) The role of cyclin E in the regulation of entry into S phase. In: Meijer L, Guidet S, Tung HYL (eds) Progress in cell cycle research, vol 1. Springer US, Boston, pp 125-139

SCANLON M, SHAW AP, ZHOU CJ et al (2000) Infection by microsporidia disrupts the host cell cycle. J Eukaryot Microbiol 47:525-531

Schmitt A, Gutierrez GJ, Lénárt P, Ellenberg J, Nebreda AR (2002) Histone $\mathrm{H} 3$ phosphorylation during Xenopus oocyte maturation: regulation by the MAP kinase/p90Rsk pathway and uncoupling from DNA condensation. FEBS Lett 518:23-28. https://doi.org/10. 1016/S0014-5793(02)02630-3

Schönenberger F, Deutzmann A, Ferrando-May E, Merhof D (2015) Discrimination of cell cycle phases in PCNA-immunolabeled cells. BMC Bioinform 16. https://doi.org/10.1186/s12859-015-0618-9

Shkap V, Bin H, Lebovich B, Pipano E (1991) Besnoitia besnoiti: quantitative in vitro studies. Vet Parasitol 39:207-213

Sugimoto K (2015) Molecular behavior of CENP-A and PCNA throughout the cell cycle in living human HT-1080 cells

Taubert A, Hermosilla C, Silva LMR, Wieck A, Failing K, Mazurek S (2016) Metabolic signatures of Besnoitia besnoiti-infected endothelial host cells and blockage of key metabolic pathways indicate high glycolytic and glutaminolytic needs of the parasite. Parasitol Res 115:2023-2034. https://doi.org/10.1007/s00436-016-4946-0
Taylor SS (1982) The in vitro phosphorylation of chromatin by the catalytic subunit of cAMP-dependent protein kinase. J Biol Chem 257: 6056-6063

Wiens O, Xia D, von Schubert C, Wastling JM, Dobbelaere DAE, Heussler VT, Woods KL (2014) Cell cycle-dependent phosphorylation of Theileria annulata schizont surface proteins. PLOS One 9(7):e103821

Velásquez ZD, Conejeros I, Larrazabal C, Kerner K, Hermosilla C, Taubert A (2019) Toxoplasma gondii-induced host cellular cell cycle dysregulation is linked to chromosome missegregation and cytokinesis failure in primary endothelial host cells. Sci Rep 9:12496. https://doi.org/10.1038/s41598-019-48961-0

Vermeulen K, Van Bockstaele DR, Berneman ZN (2003) The cell cycle: a review of regulation, deregulation and therapeutic targets in cancer. Cell Prolif 36:131-149

von Schubert C, Xue G, Schmuckli-Maurer J, Woods KL, Nigg EA, Dobbelaere DAE (2010) The transforming parasite theileria co-opts host cell mitotic and central spindles to persist in continuously dividing cells. PLOS Biology 8(9):e1000499

Zhu C, Joyce NC (2004) Proliferative response of corneal endothelial cells from young and older donors. Invest Ophthalmol Vis Sci 45: 1743-1751. https://doi.org/10.1167/iovs.03-0814

Publisher's note Springer Nature remains neutral with regard to jurisdictional claims in published maps and institutional affiliations. 